\title{
Giant Cell Tumor of Tendon Sheath in the Knee
}

\author{
Malek Ghnaimat ${ }^{1}$, Mohannad Alodat ${ }^{2}$, Mohammad Aljazazi $^{2}$, Raad Al-Zaben ${ }^{2}$, Jamal Alshwabkah ${ }^{1}$
}

${ }^{1}$ M.D., Consultant, Orthopedic Department, Jordanian Royal Medical Services, Jordan

${ }^{2}$ M.D., Specialist, Orthopedic Department, Jordanian Royal Medical Services, Jordan

\section{Type of article: Case report}

\begin{abstract}
The giant cell tumor of the tendon sheath (GCTTS) is a benign lesion which arises from the synovium of a joint, bursa or tendon sheath, with $85 \%$ of the tumors occurring in the fingers and $12 \%$ of the tumors located in large joints such as the knee and ankle. The GCTTS is usually monoarticular, slowly proliferative and rarely locally aggressive. This paper reports three cases of this rare lesion in the knee. Patients presented with painful swelling in the anterior knee, MRI showed localized soft tissue masses which were able to be excised. A follow up of the cases showed no recurrences. This case report emphasizes the importance of considering GCTTS in the differential diagnosis of soft tissue swelling and pain in large joints.
\end{abstract}

Keywords: Giant cell tumor, Knee joint, Swelling mass

\section{Introduction}

The giant cell tumor of the tendon sheath (GCTTS) is a benign lesion arising from the synovium of a joint, bursa or tendon sheath (1-3). Another name is the tenosynovial giant cell tumor, with GCTTS being the localized form of the diffuse type PVNS $(2,4)$. The GCTTS most commonly seen in the fingers is extremely rare in the knee (5). Uncertain etiology involves inflammation, trauma, toxin, allergy, clonal chromosomal abnormalities and aneuploidy. A GCTTS is characterized by a proliferation of synovial like cells with giant cells, xanthoma cells, polyhedral fibers and hemosiderin deposits $(2,4)$. Eighty-five percent of tumors occur in the fingers with $12 \%$ of tumors located in large joints, mainly in the knee. Usually patients experience painful swelling mass with no history of trauma, which emphasizes the importance of consideration in the differential diagnosis. Slow proliferation and rarely locally aggression; often recurs, but seldom has malignant behavior.

\section{Case presentation}

We report on three cases of GCTTS in the knee which were operated on one year ago in the Royal Medical Services Center by the sport injuries and arthroscopy team.

\subsection{Case no 1}

A 33 year old male patient presented with anterior knee pain and swelling localized at the patellar tendon level, had no history of trauma. His past history and medical history was clear. X ray was normal, and his MRI showed a soft tissue mass in the infrapatellar region. Anarthroscopy showed a retropatellar tendon mass excised with miniarthrotomy and a histopathology revealed GCTTS. A clinical follow up for 10 months and an MRI after 8 months revealed no recurrence.

\subsection{Case no 2}

A 25 year old female presented, as the 1st case, with no trauma history, and whose past history was irrelevant, showed an infrapatellar mass on an MRI. (Figure 1). The mass was completely excised with miniarthrotomy. The histopathlogic diagnosis was GCTTS. A follow up for 10 months revealed no recurrence.

\section{Corresponding author:}

Dr. Malek Ghnaimat, Orthopedic Department, Jordanian Royal Medical Services, Jordan.

Tel: +962772182009, E-mail: drmalekmg@yahoo.com

Received: March 20, 2016, Accepted: May 16, 2016, Published: August 2016

iThenticate screening: May 16, 2016, English editing: June 28, 2016, Quality control: August 04, 2016

(C) 2016 The Authors. This is an open access article under the terms of the Creative Commons Attribution-NonCommercialNoDerivs License, which permits use and distribution in any medium, provided the original work is properly cited, the use is non-commercial and no modifications or adaptations are made. 


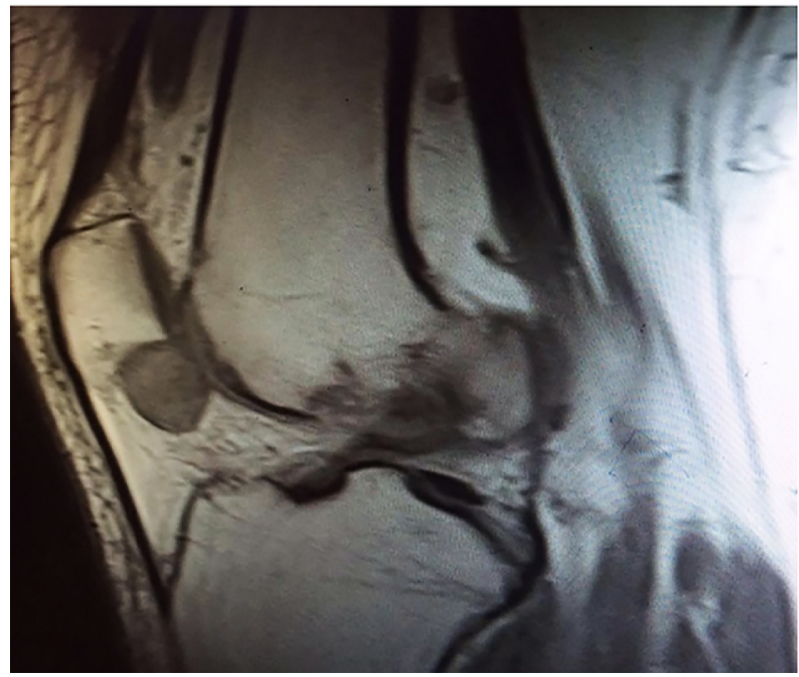

Figure 1. MRI-sagittal view showing round infrapatellar mass

\subsection{Case no 3}

A 55 year old female presented with chronic knee swelling had no history of trauma. The patient was diabetic and hypertensive on regular treatment. An X- ray showed early osteoarthritis, and an MRI reported multiple loose bodies. Arthroscopy carried out revealed no loose bodies, but three small masses arising from the synovium of the suprapatellar region which were excised arthroscopically with the histopathology diagnosis of GCTTS (Figure 2). A follow up was for 6 months only, and with no recurrence, the patient did not return to the clinic.

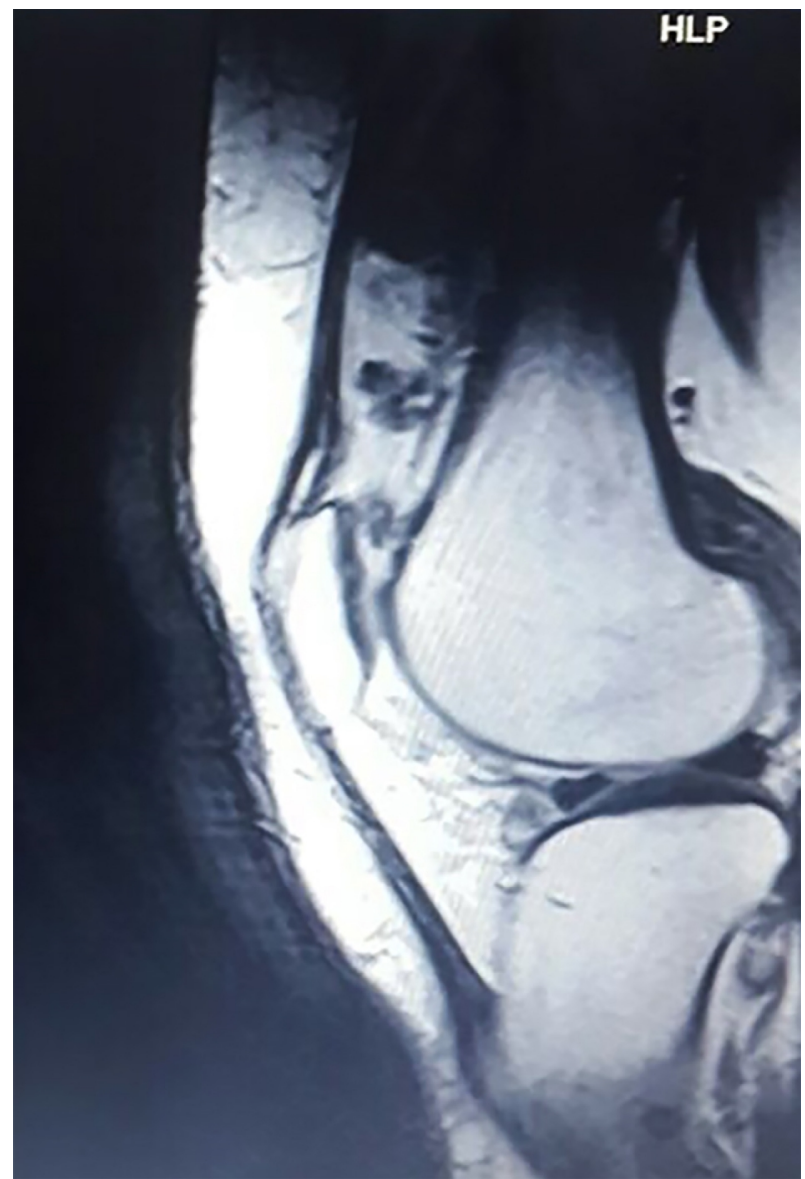

Figure 2. MRI showing multiple suprapatellar masses 


\section{Discussion}

The GCTTS is a benign soft tissue tumor arising from the synovium of a tendon, bursa or joint. It is a localized form of tenosynovial giant cell tumor seen in most cases in the fingers (2-4). The knee joint is the most common joint of involvement among the rare extra finger involvement (3-7). GCTTS may occur at any age but mostly at ages between 30 and 50, with a 2:1 female predominance $(2,3)$. The usual presentation is knee swelling, usually slowly progressive with zeroto mild pain, and rare history of trauma $(3,5,7)$. Plain radiography is usually free (7). The MRI is the gold standard to diagnose the masses in or around the knee joint (4-7). Local excision with arthroscopy or arthrotomy is the treatment of choice $(1,3,5-7)$. Local recurrence was reported to be $10-20 \%$ with the reason of inadequate primary resection and some authors recommend re-excision accompanied by radiation $(1,3,4,7)$.Our follow up was for about ten months with no clinical or MRI signs of recurrence $(6,7)$.

\section{Conclusions}

GCTTS is a benign lesion arising from the synovium of tendon sheath mainly in fingers, but can be present in large joints mainly in the knee. A knee MRI is the diagnostic tool, and a complete excision is curative with rare cases of recurrence .Our aim of the study is to consider GCTTS in the differential diagnosis of pain and swelling of large joints particularly the knee.

\section{Acknowledgments:}

The authors would like to thank the staff at Prince Hashem Hospital who cooperated with me to finish this issue including the radiology and the histopathology teams, and all members of the sports injuries and arthroscopy division of our orthopedic department.

\section{Conflict of Interest:}

There is no conflict of interest to be declared.

\section{Authors' contributions:}

All authors contributed to this project and article equally. All authors read and approved the final manuscript.

\section{References:}

1) Rukavina I, Ćaleta D. Giant-cell tumour of the tendon sheath: A review. Paediatric \& Geriatric Orthopaedics. 2014; 2(2): 11.

2) Giant cell tumor of tendon sheath. Humpath.com - Human pathology Wednesday 27 October 2004: 19962015.

3) Shankar V. Soft tissue tumors Jiant cell of tumor of tendon sheath-diffuse type, last major update August 2012. Available from: http:/www.pathologyoutlines.com/topic/softtissuegctdiffuse.html

4) Verheyden JR, Gellman H. Giant cell tumor of tendon sheath, Medscape reference. Last Updated. 2014.

5) Pedrinelli A, Pires de Camargo O, Bispo Barreto R, Moldenhauer D, Pedrinelli R. Giant cell tumor of tendon sheath. Acta ortop bras. 2007; 15(3). doi: 10.1590/S1413-78522007000300012.

6) Beytemür O, Albay C, Tetikkurt US, Oncü M, Baran MA, Cağlar S, et al. Localized Giant Cell Tenosynovial Tumor Seen in the Knee Joint. Case Rep Orthop. 2014; 2014: 840243. doi: 10.1155/2014/840243. PMID: 24716065, PMCID: PMC3971503.

7) Sukeik M, Sharda P, Maheswaran S. Giant cell tumor of the tendon sheath in a knee. The Internet Journal of Orthopedic Surgery. 2007; 9(2). 